\title{
The Impact of Task-Based Instruction Program on Fostering ESL Learners' Speaking Ability: A Cognitive Approach
}

\author{
Mohammad Mohammadipour \\ English Department, Faculty of Modern Languages and Communication, University Putra Malaysia, Malaysia \\ E-mail: m.mohammadipour87@gmail.com \\ Sabariah MD Rashid (Corresponding author) \\ English Department, Faculty of Modern Languages and Communication, University Putra Malaysia, Malaysia \\ E-mail: smrashid@upm.edu.my
}

Doi:10.7575/aiac.alls.v.6n.2p.113

Received: 05/12/2014

URL: http://dx.doi.org/10.7575/aiac.alls.v.6n.2p. 113

Accepted: 02/02/2015

\begin{abstract}
Adopting a direct approach to contrive sufficient focus on form (accuracy) would facilitate interlanguage development without decreasing the naturalness of communication that communicative tasks can generate. This study aimed to determine the effectiveness of a proposed task-based instruction programme within a cognitive approach in fostering overall speaking proficiency of undergraduate students. 72 students from several public universities participated in the study, which employed an experimental design. The students of the experimental group received training through the proposed task-based instruction programme for three months while those in the control group received regular instruction. The preliminary English Test (PET) was administered as a pre- and post-test measure of speaking proficiency. Findings of the study showed a significant improvement in the overall speaking proficiency of the students who were exposed to the proposed programme. The findings suggest the potential of the task-based programme in enhancing undergraduate students' overall speaking proficiency.
\end{abstract}

Keywords: The cognitive approach, speaking skills, task based instruction, TESL, the communicative approach

\section{Introduction}

\subsection{Introduction}

Over the past decades, English has moved toward paramountcy so that it has come to be known as the quality global language. Speaking is one of the four well-known language skills i.e. reading, writing, listening and speaking. Bahrani (2011) argues, speaking is the most freuently used language skill, it is used twice as much as reading and writing in our daily communication.

Fostering speaking skills is one of the outstanding elements of almost any EFL/ESL program. Graves (2008) and Nazara (2011) argue that language is primarily spoken, and to many people, mastering speaking abilities is the ultimate goal of acquiring a foreign or second language. To Glover (2011), it is by this skill that success in learning a Language is measured.

A reveiw of the different approaches to teaching speaking skills revealed that there are two dominant perspectives: a direct approach and an indirect approach. The direct approach was an answer to the dissatisfaction with the grammar translation method, which teaches students grammar and vocabulary through direct translations and focuses on the written language. It is an attempt to set up conditions that imitate mother tongue acquisition, which is why the beginnings of these attempts were called the natural approach. The approach helps learners focus on specific elements of speaking proficiency, which are isolated and practiced (Hughes, 2002). The indirect approach, on the other hand, helps learners focus on communicative tasks mediated through negotiation and the sharing of information. It tries to meet individuals' oral communication needs that may arise in conversation management (Ellis, 2003).

Gorsuch (2011) argues that, communicative tasks, representing the indirect approach, can have a positive effect on teaching speaking. However, this over-emphasis on communication during performing tasks increases the risk of a greater reliance on ready-made acquired and probably incorrect language which, becomes resistant to change and hinders language development. Hence, the need emerges for adopting a direct approach to contrive sufficient focus on form (accuracy) and to enable the development of interlanguage without decreasing the naturalness of the communication that tasks can generate. To achieve this goal, the cognitive approach focuses on how tasks are implemented to maximize chances of focus on form (Derwing, Murray, \& Thomson, 2008 and Glover, 2011).

In the light of the cognitive appraoch assumptions, This study employed a three-stages for Freshmen university students. First, students are exposed to a pre- task stages which aims at increasing the chance that some restructuring occur in their language system (Ellis, 2003). Then, in the during- task stage, students will be engaged in the task, plan 
for reporting the task results, and report the task output in front of their peers. Finally, the post- task stage aims at the raising of linguistic consciousness on the basis of which learners can make conclusions about the spoken language.

The current study attempts to develop the necessary speaking skills for freshmen university students through the use of a task- based proposed program designed in the light of the cognitive approach to language learning.

The significance of the present study lays in the fact that it was the first attempt in Malaysia to bring about integration between communicative tasks and the cognitive approach throughout a suggested program aiming at developing Malaysian ESL university level students' speaking skills. The current study was, hence, an attempt to overcome the shortcomings in teaching the speaking skill, which is considered a basic skill. Besides it emphasized the importance of providing ESL freshmen university students with activities and opportunities to raise their awareness of speaking underlying skills. This study, also, proposed the use of some strategies to help freshmen university students understand how to plan for speaking, monitor their speaking performance, perform publicly in front of their peers and analyze spoken discourse characteristics.

\subsection{Purpose of the Study}

This study aimed to:

1- Measure the effectiveness of the proposed task- based program in the light of the cognitive approach in developing freshmen university students' overall speaking proficiency.

2- Compare the effectiveness of the proposed task-based program in the light of the cognitive approach and traditional method of taching English in Malaysia in developing freshmen university students' overall speaking proficiency.

\section{Theoretical Background}

\subsection{Integrating communicative tasks and the cognitive approach}

The cognitive approach and communicative tasks also called socio-cultural and information processing theories (Kasper, 2001: 525). Communicative tasks are generally aimed at fostering students' abilities to achieve communication in real time. McCarthy and Carter (2001) argue that approach it cannot be presumed that achieving communicative effectiveness via task performance will set up the essential conditions that support longer-term language acquisition.

There is a need to integrate the communicative approach (tasks) is applied in a more systematic way to help develop SL learners' speaking ability and interlanguage system. Furuta, (2002) argues that the integration between the two perspectives is called a principled communicative approach. The cognitive approach theorists suggest that task-based learning should manage the learner's focus of attention and that there should be reasonable progress towards the three goals of fluency, accuracy, and complexity (Ellis, 2003: 130). Moreover, as the starting point for planning and designing a framework for task -based instruction conforming to the cognitive approach three imperative general procedures were proposed, these are as follows: (a) Choosing a range of target structures: Providing fertile conditions through identifying a set of target structures, skills or elements which may be made prominent in attentional term can enhance the chance of language development. (b) Selecting and sequencing tasks to achieve balanced goal development: Regarding principled communicative approach sequencing tasks base on approximate real life language use situations will cause an effective balance between fluency and accuracy and the prospect for previous restructuring to be applied (Badr, 2008; Romero, 2006; Zhang, 2009). (c) Implementing tasks to manipulate attentional focus: This means that there is a need to enhance learners' attention on form in the context of meaningful language use (Aliakbari \& Jamalvandi, 2010).

Pre-task Stage: Willis (1996) argues that by giving learners a pre-task to do we can equip them with the language they really need. Planning; consciousness raising and teaching are three major types of pre-task activities.

During -task stage: The prominent factor affecting performance during the task is the choice of the task itself. Tasks should not be so easy that learners do not engage seriously nor should be tasks so difficult that excessive mental processing is required (Kumaravadivelu, 1993 and Willis, 1998).

Furthermore, teachers can manipulate the difficulty of a task, and influence on the way in which attention by making some decisions. Generally, there are two aspects of during-task activity: manipulation of attention and the extended task procedure.

Post -task stage: The primary assumption at this stage is that learners have to be reminded that fluency is not the only goal during-task completion, and that restructuring and accuracy also have importance. So post- task activities provide another means of inducting efficient use of attention during-tasks (Koester, 2000: 176).

Finally, after the two previous stages of pre-task and during- task, the primary assumption at this stage is that fluency is not the only goal during-task completion, and learners have to be reminded that accuracy and restructuring also have significance (Bahrani, 2011). The intention of focus on language at this stage is that any language which is focused upon is necessary for a communicative purpose and relevant to learners. So post- task activities provide some degree of language focus where a variety of activities can be engaged in (Koester, 2000: 176).

\subsection{Research Questions and Hypotheses}

The study attempted to address the following main questions: 
1- Is there a statistically significant difference between the mean scores of the experimental group exposed to the proposed task-based program in the light of cognitive approach, and the control group receiving regular instruction on the post-test in overall speaking proficiency?

2- Is there a statistically significant difference between the mean scores of the experimental group on the speaking pretest and post-test in overall speaking proficiency?

With regard to these research questions, the following research hypotheses were formed:

1- There is a statistically significant difference between the mean scores of the experimental group exposed to the proposed task-based program in the light of cognitive approach, and the control group receiving regular instruction on the post-test in overall speaking proficiency in favor of the experimental group.

2- There is a statistically significant difference between the mean scores of the experimental group on the speaking pretest and post-test in overall speaking proficiency in favor of the post-test scores.

\section{Methodology}

\subsection{Participants}

A group of seventy-two first year University students were randomly selected from one of the Malaysia state universities, namely Universiti of Putra Malaysia, in the academic year 2013-2014 specificly, (36 students in the experimental group and 36 students in the control group).

Students' age in both groups ranged from eighteen to nineteen. All the participants in the sample of the current study had been learning English as a second language for seven years. The students thus constituted a homogenous group in terms of their learning history and English proficiency.

\subsection{Materials}

The main materials applied for the experimental group were some supplementary video files extracted from TED conferences, to which students were exposed before doing the task. TED is a nonprofit devoted to ideas worth spreading. It started out in 1984 as a conference to bring together people from three domains of: technology, entertainment and design. Since then its scope has become ever broader. All the video files were selected from TEDTalks according to the students' level and according to the content or spoken genre tackled by each task. While selecting the video files, the researcher took into account the following criteria:

- They were relevant to students' background knowledge and culture.

- They were authentic, representing real life spoken discourse and including natural characteristics of spoken discourse such as (fillers, hesitation markers, fixed expressions, ellipsis, vague language, ,...etc).

- They could lend themselves to analysis and close examination as a means of raising student's awareness of different aspects of spoken discourse.

The main site students were referred to was: http://www.TED.com

\subsection{Instruments}

The present study made use of the Cambridge Preliminary English Test (PET) as a pre-post speaking test to measure freshmen university students' overall speaking proficiency.

\subsubsection{Objectives of the test}

The PET speaking test was used as a pre-test, prior to the program implementation to make sure that students of both groups were at the same speaking level before starting the experiment, and hence the progress achieved by the experimental group could be attributed to the program they had been exposed to. As a post-test, The PET speaking test was used to investigate the effectiveness of the proposed task- based program in the light of the cognitive approach in developing freshmen university students' overall speaking proficiency.

\subsubsection{Description of the test}

The PET Speaking test is conducted by two examiners (an Interlocutor and an Assessor) with pairs of candidates. The Assessor takes no part in the interaction. It takes 10-12 minutes for each pair of candidates. The Speaking test is divided into four parts.

The test sections/tasks were as follows:

\section{Part 1}

In this part, candidates interact with the Interlocutor, using the language normally associated with meeting people for the first time. Candidates are asked to talk about, for example, their home town, school, occupation, family, interests, etc.

\section{Part 2}

In this part, the two candidates interact with each other. The Interlocutor describes a situation to the candidates, in response to which they are required to make suggestions, discuss alternatives, state preferences, etc. Candidates are given a visual prompt to help stimulate ideas for their discussion. 


\section{Part 3}

In this part, each candidate in turn is given a colour photograph to talk about. Candidates should be encouraged to talk about the setting, people and activities. Specialised vocabulary is not expected at PET level, but candidates should be able to paraphrase. The two photographs are linked thematically to establish a common starting point for Part 4.

\section{Part 4}

In this part, the theme of the photographs in Part 3 (for example, holiday activities) is used as a starting point for a general conversation about the candidates' likes and dislikes, experiences and habits. The Interlocutor initiates the discussion but the candidates are expected to talk between themselves. They should be able to talk about their interests and reasons for liking or not liking something. The Interlocutor will use prompts if the discussion fails to develop.

Table 3.1 Functions/ micro function measured throughout the test tasks

\begin{tabular}{|c|c|c|c|}
\hline Part & Focus & Skills & Time \\
\hline 1 & Giving personal information & $\begin{array}{l}\text { Socialising, interacting and giving personal } \\
\text { information }\end{array}$ & $2-3 \mathrm{mins}$ \\
\hline 2 & Simulated situation & $\begin{array}{l}\text { Expressing and finding out attitudes, discussing } \\
\text { alternatives, agreeing/disagreeing, making choices }\end{array}$ & $2-3 \mathrm{mins}$ \\
\hline 3 & Describing a photograph & $\begin{array}{l}\text { Giving information, describing, structuring } \\
\text { discourse, comparing and contrasting, paraphrasing }\end{array}$ & 3 mins \\
\hline 4 & $\begin{array}{l}\text { General conversation based on } \\
\text { theme from Part } 3\end{array}$ & $\begin{array}{l}\text { Giving and obtaining factual information, } \\
\text { expressing and finding out opinions and attitudes, } \\
\text { structuring discourse, } \\
\text { Socializing }\end{array}$ & 3 mins \\
\hline
\end{tabular}

\subsubsection{Test Administration}

\subsubsection{Scoring the test}

Throughout the Speaking test candidates are assessed on their language skills, not their personality, intelligence or knowledge of the world. Candidates at this level are not expected to be fully fluent or accurate speakers, but they are expected to be able to interact appropriately, develop the conversation and respond to the tasks set. The language of the Speaking test is carefully controlled to be accessible to candidates at this level; if candidates do not understand a question or an instruction they should ask for repetition or clarification and they will normally get credit for using this strategy. Similarly, they will get credit for using paraphrase to supplement any inadequate linguistic resources.

Throughout the test, The interlocutor awards a global mark out of 25 according to five criteria which are interpreted at PET level: Vocabulary, Grammar, Pronunciation, Discourse Management, and Interactive Communication. assessment is based on performance in the whole test, and is not related to performance in particular parts of the test.

\subsubsection{Psychometric Requirements}

\subsubsection{Test Reliability:}

Following the implementation of PET speaking in pre test stage, the recorded samples of the subjects' performance were assessed by four raters and two raters with the closest means of scores were selected for both pre and post test assessment. Next, to guarantee the reliability of the rating process, inter-rater reliability was computed. It was 0.85 which appeared as an acceptable value of inter-rater reliability.

\subsubsection{Test Construct Validity}

The score on the Speaking test is given on the basis of the following criteria: Grammar and Vocabulary, Discourse Management, Pronunciation and Interactive Communication.

\subsection{Grammar and Vocabulary}

This scale refers to the accurate and appropriate use of grammatical forms and vocabulary. It also includes the range of both grammatical forms and vocabulary. Performance is viewed in terms of the overall effectiveness of the language used in dealing with the tasks.

\subsection{Discourse Management}

This scale refers to the coherence, extent and relevance of each candidate's individual contribution. On this scale the candidate's ability to maintain a coherent flow of language is assessed, either within a single utterance or over a string of utterances.

Also assessed here is how relevant the contributions are to what has gone before.

\subsection{Pronunciation}

This scale refers to the candidate's ability to produce comprehensible utterances to fulfill the task requirements. This includes stress, rhythm and intonation, as well as individual sounds. Examiners put themselves in the position of the 
non-language specialist and assess the overall impact of the pronunciation and the degree of effort required to understand the candidate.

\subsection{Interactive Communication}

This scale refers to the candidate's ability to use language to achieve meaningful communication. This includes initiating and responding without undue hesitation, the ability to use interactive strategies to maintain or repair communication, and sensitivity to the norms of turn-taking.

\subsection{Procedure}

The experiment lasted for eleven weeks (approximately three months) through which both the experimental and the control groups participated in their classes once a week. Each class lasted for 120 minutes.

The researcher taught the experimental group students himself based on proposed task- based program in the light of cognitive approach. On the other hand, the control group received regular instruction by a regular classroom teacher. According to regular instruction, the control group students were given little communicative opportunity to practice the speaking skills. Students rarely practiced any pre-speaking activity that aimed at teaching them the characteristics of the spoken language and they were never guided to use planning before the speaking activities. Besides, the students receiving regular instruction were not offered any activities to help them analyze or reflect on their own performance. Before and after the treatment a pre/ post speaking test was given to the two groups.

\subsection{The program}

\subsubsection{Content of the program}

The speaking skills were taught throughout nine units comprising eleven lessons. Each unit focused on a particular main function or a certain spoken genre. Throughout the lessons, students were required to perform the following tasks: Describe and find the differences. Discuss ideas, views and opinions. Solve problems and find the solutions for given situations. Conduct interviews to obtain information from each other. Exchange information throughout information gap tasks. Narrate stories to their peers guided or not guided by pictures. And, role play situations to practice social/ interactional functions.

Sample lessons from the program were given to four ESL specialists who approved it and suggested: Giving students more practice on the speaking skills and allocating more time to teaching the program will be appropriate.

\subsubsection{The proposed teaching strategy:}

The teaching strategy adopted in this study was designed in the light of the integration between communicative tasks and the cognitive approach. According to this teaching strategy, each speaking lesson was divided into three main phases: pre-task phase, during-task phase and post- task phase. These phases could be explained in detail as follows:

\subsubsection{Pre-task stage}

For each task, more than one pre-task activity was used to get students well prepared for the task. For instance, teaching before the task was accompanied by planning so that students could benefit from the information they had to learn.

Consciousness raising activities were sometimes accompanied by planning or teaching. The harder the task, the more consciousness raising activities and planning were provided.

\subsubsection{During the task}

At this phase, the students participated in the task and the focus was on communicating meaning. Although the teacher worked as a facilitator most of the time at this stage, he helped students cope with specific problems as they came up in these ways: He provided clarification for the students so they wouldn't lose the thread of what was going on. He prevented digression or native language use. And, he ensured that all students had a chance to participate in the task.

At this stage also, one of the students was assigned for each peer/ group to observe her peers' performance and write some comments concerning problems in grammar, pronunciation, vocabulary and organization of discourse. Moreover, students' performance during performing the task was recorded by the teacher. Practically, not all the students could be recorded, so in each lesson one or two pairs/ groups were recorded for subsequent analysis. Moreover, the teacher walked around to gather common observations about each group to be handled later on with the whole class at the posttask stage.

\subsubsection{Post-task stage}

At the post-task stage Students were asked to conduct self/peer evaluation of the tapes recorded during the task. In addition, the observer assigned during the task was asked to give a general feedback about his/her group's performance. Not all the recording was analyzed but students were asked to use just an extract of it to prepare and work through.

\subsection{Data collection}

The students were examined according to PET speaking test instructions. Required conditions for the test administration were provided by the university administration as far as possible.

The pre- test administration started on the 29th of September, that is, 7 days prior to the experiment. The pre-test ended on the 6th of October. The post- test was administered on the 30th of December 2013 and lasted for 8 days, so it ended on 7 th of January. It was administered to both the experimental and the control groups. 


\subsection{Data Analysis}

The collected data were analyzed using the program Statistical Package for Social Sciences (SPSS). The analyses included descriptive statistics including means, and standard deviations. For comparative analysis independent sample ttest and paired sample t-test were used.

\section{Results and Discussion}

4.1 - test results of the pre- test comparing the control and experimental groups mean scores in overall speaking

To control variables prior to implementing the treatment Student scores from the pre-test were systematically entered into a computer for quantitative analyses, which was analyzed using the Statistical Package for the Social Science (SPSS). Consequently, an independent-sample t-test was administered to find out whether there were statistically significant differences between the control and the experimental groups in terms of speaking proficiency.

Table 1. T- test results of the post- test comparing the control and experimental groups mean scores in overall speaking

\begin{tabular}{|c|c|c|c|c|c|c|}
\hline Group & $\mathrm{N}$ & Mean & Std. Deviation & $\mathrm{T}$ & Df & Sig (2-tailed) \\
\hline Control & 36 & 10.61 & 2.18 & & & \\
\hline Experimental & 36 & 11.50 & 2.37 & -1.65 & 70 & 0.105 \\
\hline
\end{tabular}

As shown in table (1), There was no significance difference in scores for control $(M=10.61, S D=2.18)$ and experimental group, $M=11.50$,

$S D=2.37 ; t(70)=-1.65, p=0.11$ (two-tailed). The magnitude of difference in the means was small (eta squared $=$ .006).

The analysis shows that two groups were approximately at the same level of performance in speaking and therefore any variance between the two groups that may occur after the implementation of the program will be attributed to it.

\section{$4.2 T$ - test results of the post- test comparing the control and experimental groups mean scores in overall speaking}

In the light of the research objectives, two hypotheses were stated:

1.There are statistically significant differences between the mean scores ofthe experimental group exposed to the suggested task-based instruction program, and the control group receiving regular instruction on the post-test in overall speaking proficiency in favor of the experimental group.

2. There are statistically significant differences between the mean scores of the experimental group on the speaking pretest and post- test in overall speaking in favour of the post- test scores.

To test the first hypothese, an independent sample t-tests was employed to compare the mean scores of the two groups on the post- test.

The results of the $\mathrm{t}$ - tests proved to be statistically consistent with the hypothesis.

Table 2. T- test results of the post- test comparing the control and experimental groups mean scores in overall speaking

\begin{tabular}{llllllc}
\hline Group & $\mathrm{N}$ & Mean & Std. Deviation & $\mathrm{T}$ & Df & Sig (2-tailed) \\
\hline Control & 36 & 13.52 & 2.0 & & & \\
\cline { 1 - 5 } Experimental & 36 & 19.19 & 2.22 & -11.34 & 70 & 0.00 \\
\hline
\end{tabular}

As shown in table (4.2.), There was significance difference in scores for control $(M=13.52, S D=2.0)$ and experimental group, $M=19.19$,

$S D=2.22 ; t(70)=-11.34, p=0.00$ (two-tailed). The magnitude of difference in the means was very large (eta squared $=0.64$ ).

Table (2) supports first hypothesis as it shows that there were statistically significant differences between the mean scores of the control and the experimental groups on the post- test in overall speaking proficiency in favor of the experimental group. Furthermore, the calculated effect size value of the proposed program on students' overall speaking shows that the proposed program had a large effect on the experimental group students' overall speaking performance on the post- test as compared to that of the control group students receiving regular instruction. 
In order to verify the validity of second hypothesis, $t$ - tests for paired samples were used. The $t$-test results proved that there were statistically significant differences between the pre- posttests mean scores of the experimental group in overall speaking proficiency. Therefore, the second hypothesis was accepted. The following tables show this statistical significance.

Table 3. T- test results comparing the pre- test vs. post- test means for the experimental group in overall speaking

\begin{tabular}{|c|c|c|c|c|c|c|}
\hline Group & $\mathrm{N}$ & Mean & Std. Deviation & $\mathrm{T}$ & D.F. & Sig (2-tailed) \\
\hline Pre-test & & 11.50 & 2.37 & & & \\
\hline Post-test & 36 & 19.19 & 2.22 & -26.82 & 35 & 0.00 \\
\hline
\end{tabular}

As indicated in Table 3, There was statistically significant difference in PET speaking test scores from time 1 ( $M=$ $11.50, S D=2.37)$, to time $2(M=19.19, S D=2.22), t(35)=-26.82, p<.005$ (two tailed). The eta squered statistics (.50) indicated a large effect size.

\section{Discussion}

As it was noticed, the study came up with some notable results deserving further considerations and discussions. Therefore, in the following sections the results of the study are discussed and in the next section, some of the most important conclusions drawn from the study will be presented and discussed.

The results of the study proved that proposed task-based instruction program in the light of cognitive approach was effective in fostering the experimental group students' overall speaking performance. This was understandable in the support gained for the two hypotheses of the study.

First, there were statistically significant differences between the mean scores of the experimental group exposed to the proposed task-based program, and the control group receiving regular instruction on the post-test in overall speaking proficiency in favor of the experimental group. The analysis of the $t$-test revealed that $t=-11.34$. Therefore, the program contributed to the students' development in terms of overall speaking proficiency.

Second, there were statistically significant differences between the mean scores of the experimental group on the speaking pre-test and post-test in overall speaking proficiency in favor of the post-test scores, since $t=-26.82$. So the second hypothesis was supported.

As it was mentioned before throughout the test, the interlocutor awards a global mark according to five analytical criteria: vocabulary, grammar, pronunciation, discourse management, and interactive communication. Regarding the result of study, students' progress might be attributed to several factors. The communicative tasks based on the cognitive approach helped the students practice many cognitive strategies and processes. It engaged the students to analysize (focus on form) and synthesis (actual communication) through three stages (pre, during and post-task).

\subsection{Pre-task stage:}

\subsubsection{Consciousness Raising Exercises}

The students reported that adopting a discovery approach through analyzing the TED-Talks was motivating as it helped them to form and test hypotheses about spoken language rules. It also offered them to see how native language speakers perform in real-life situations.

Furthermore, raising students' awareness by adopting a discovery approach through analyzing the TED-Talks enabled students to: (a) see how grammatical rules are applied appropriately by native speakers in real-time speech. (b) acquire a range of vocabulary related to the speaking genres and topics they had to tackle. (c) extract word collocations and understand that words are combined together according to certain conventional rules. (d) understand how when we speak, we use lexical phrases that are learned and retrieved as units rather than combining words each time we speak. (e) identify some special characteristic of spoken vocabulary such as: vague language and words that are only used in the spoken discourse (i.e. "pretty big" instead of "very big"). And (f) recognize some individual characteristics of spoken grammar, which distinguishes it from written grammar such as: ellipsis, tag questions, contractions, and short incomplete sentences called "utterances".

In addition, the authentic samples, students were exposed to, helped them indirectly improve the organization of their speaking as they could recognize how native speakers (a) organize discourse through following certain routines so that students can easily follow the sequence of what is said, (b) use grammatical and lexical references appropriately to refer to people and objects so students can keep track of them, (c) provide enough supporting details, reasons and examples to support the main idea or to justify their opinions, (d) summarize the main idea given in speech and finally (e) move smoothly from one idea to another through the use of adequate discourse markers signaling cohesion either at the macro level (between main ideas) or at the micro level (within utterances).

Throughout consciousness raising exercises, the students noticed the characteristics of the speech stream and the sound system. The students' attention was also drawn to how sounds are linked in spoken language and how sounds change, as the result of the influence of neighboring sounds (assimilation). 
Besides, analyzing the provided authentic video tapescripts, before participating in the task helped students see how native speakers; (a) manage turn-taking in conversation, (b) relate his/her turn to that of the interlocutor, and (c) encourage others to speak through showing interest, asking further questions, backchanneling and commenting.

\subsubsection{Teaching}

In addition, the direct instruction at the pre-task stage helped to trigger topic related vocabulary, grammar, pronunciation, discourse and pragmatic skills. This increased the students' motivation, involvement, and willingness to do the required activities and practice speaking

Teaching and consciousness raising activities, at the pre-task stage, helped draw students' attention to important words related to the task to be performed. Most of the teaching was done inductively through encouraging students to elicit words appropriate to different stages of the genre. The students were always taught how to deal with expressions as a whole and look for words that precede or follow each vocabulary item.

In addition, throughout teaching the students noticed the importance of choosing words appropriate to the social context. At the pre-task stage students' attention was drawn also to the grammatical points relevant to every genre. For instance, the present simple tense was stressed to help students express and inquire about personal information, describe personality and appearance or talk about daily routines. Similarly, modal verbs were tackled deeply to help students sound more polite in all social every day encounters.

Moreover, throughout teaching, the students could notice discourse markers including those signaling the introduction of a topic, a shift to a new topic and a summary of the topic. They also, learned the meaning and the use of conversational discourse markers such as (well, now, anyway...etc) used to maintain conversational coherence, thus, employing these markers in their speaking as well. Furthermore, instruction given to students helped them organize, notice and understand the way the content of their conversation is conveyed. This included presenting the conversation typical sequence for performing various routines and explaining how each turn is linked to the previous one and inviting the next one. At this stage, the students were also given instruction about how to keep the conversation going.

\subsubsection{Planning}

Planning at Pre-task stage helped the students to handle communicative pressures during the task it also confident them to produce more fluent and complex language. Besides, on- line planning encouraged students to focus on accuracy while they were speaking. Moreover, at the planning stage before doing the task the students had to determine the words and words collocations needed to do the task. This helped to draw their attention to how to select words appropriate to the task to be done.

Additionally, planning helped the students identify some strategies they can use if they couldn't find the appropriate word such as circumlocution that led to a greater lexical variety in the students' responses. Requiring the students to plan for the upcoming task by determining the grammar needed in terms of tenses, word order, and structure of complex utterances was very effective. It helped draw their attention to form and accuracy rather than focusing solely on fluency.

In addition, the planning executed to present task output helped students refocus on discourse by thinking of how to present their speech to others in an adequately organized manner. Moreover, requiring the students to plan through determining how they could pronounce different expressions and how they would vary pronunciation according to their purpose and feelings was vital. It helped raise the students' awareness and draw their attention to accuracy of pronunciation and thus facilitated the use of different pronunciation features during real online spoken performance.

\section{2 during-task stage}

During performing the task, students employed all the learned speaking skills spontaneously and the planning they did to perform a real task without the teacher's intervention.

At this stage, students could use the grammatical structures and vocabulary learned before the task. They negotiated meaning which helped them employ various strategies to ask for clarification or explanation of difficult words. They tested their hypotheses about pronunciation. And employed what they had noticed about the organization of spoken discourse spontaneously and fluently in an actual situation.

In addition, giving students a chance to present the final task results in front of their peers helped them overcome their fear of public speaking and hence increased their proficiency.

\subsection{Post-task stage}

At the Post-task stage, various activities remedied students' common errors and a wide repertoire of opportunities were provided to practice and focus on the speaking skills.

\subsubsection{Self/ Peer-Evaluation through Video Recorded Speaking Tasks}

Researcher's informal interviews with the students revealed that the use of video camera, as a technological tool, had a positive impact on their viewing and evaluating of their own or their peers' speaking tasks.

In addition, the students reported that seeing their video recorded speeches and working independently at their own pace help them to overcome their anxiety. According to them this process enabled them to identify their problems and keep their own record of progress.

Furthermore, Analysis of the video-recordings of the students' speaking tasks and the students' awareness of the criteria according to which their speaking will be evaluated led them to recognize general patterns of errors they made in 
spontaneous speech and made them work hard to meet these criteria. Hence students identified their points of strengthes and weaknes precisely and comprehensively.

\subsubsection{Supportive feedback}

At the post-task stage, students were encouraged to be active and autonomous learners as they were provoked to discover the rules by themselves via the set of activities aiming at analyzing spoken discourse. They were also triggered to practice the speaking skills learned in a more conscious and deliberate manner. These activities stressed students' common points of weakness in terms of speaking sub-skills, and remedied them.

The supportive feedback the students received throughout the task started at the during- the task stage by helping students report the results of the task to each other. Then, this feedback occurred again at the post-task stage as the teacher and the students provided useful comments to each other after they self-evaluated themselves and their peers. Noticeably, the feedback the students received throughout the task cycle was based on the integration of self-correction, interactive peer correction and supplementary teacher intervention. This feedback did not only focus on the weak aspects of speaking performance, but they also highlighted the strong aspects, thus helping students improve their speaking and increase their self confidence and motivation at the same time.

In this way, the teacher's feedback through the use of previously agreed upon criteria helped the students integrate the correct more complex structures in their existing language system.

For instance, the post-task stage included many activities, in which the students' common pronunciation errors during the task, including those resulting from the interference of the mother language were remedied.

With respect to different genres, the focus points of pronunciation were derived from the content of each task. Therefore, the students could learn a lot about the pronunciation rules that differed according to the genre, intention of the speaker, and relation between the speaker and listener. In particular, the pronunciation rules addressed in each genre were different and specific. for example, pronunciation of question tags was stressed to help the students express and inquire about personal information, rising intonation to express interest during exchanging personal information tasks, and to show politeness in tasks including asking for permission or making requests.

\section{Conclusions, Pedagogical Implications, and Suggestions for Further Research}

\subsection{Conclusions}

Based on the significant results of this study, the following conclusions can be made: The present study provides evidence that integrating both the cognitive approach strategies and task-based instruction can foster freshmen university students' speaking proficiency.

The change in the teacher's role from an authoritarian to a discussion organizer, a facilitator and a language adviser allows students to share more responsibilities for their learning, express themselves freely and become the centre of the learning process.

In the light of the result of this study, it can be concluded that balanced development in different areas of language performance accuracy, fluency and complexity will lead to a sustained progress in speaking proficiency. So complexity (acquiring new rules and restructuring the language system in terms of speaking skills) would be accompanied by the development of control over the newly acquired skills and the integration of these skills into fluent performance (Kessler, 2010).

To accomplish this balance in terms of speaking both Accessibility and Analyzability have to be developed. Accessibility is a memory based system which enables the learner to keep up with ongoing discourse using ready made lexical language, while Analyzability helps the learner rely more on rule based system to produce language thus enables him to be more flexible.

Triggering the students to focus on form- whether in terms of language, discourse or functions- before or after the task enables language development to proceed without decreasing the naturalness of the communication that tasks can generate. It engages them in a process of discourse analysis which promotes their reflection ability and thus enhances their speaking sub-skills effectively. This is supported by Skehan (2002) and Bahrani (2011).

Providing SL learners with explicit instruction before the task does not only foster their understanding of spoken discourse characteristics, but it also helps them to use these characteristics and their underlying skills in actual performance. It enables them to understand and prepare themselves well to the task and hence foster their spoken performance. This is consistent with the results of other studies such as Zhang, (2009).

Using raising awareness activities before engaging the students in communicative tasks helps improve their grammatical, discourse and pragmatic competences, as it shows them how the spoken interaction takes place in real life situations. This is supported by Dincer, Yesliyurt and Takkac (2012).

Helping students to plan before speaking and interacting orally proved to be effective in enhancing students' speaking performance in terms of all speaking skills. It can lead SL learners to produce more developed speech. It helps also to ensure that any change occurring in the language system can be drawn upon during oral language use and production. This is consistent with the results of other studies such as Yuan and Ellis (2003).

Self/ peer-evaluation after performing tasks, enables students to direct and control their own learning as they pay more attention to their points of strength and weakness and hence motivate them to become more willing to self-correct and 
rebuild their underlying language system. This encourages students to be more involved in planning and organize their future learning.

This is supported by Kirkgoz, (2011). This self-evaluation process proved to be most effective when learners are aware of the criteria according to which their performance can be evaluated. This is supported by Murat (2012).

There is evidence that exposing students to authentic texts via spoken language corpus driven materials, helps to raise their consciousness and encourages them to draw insights especially about the lexical phrases and expressions used in authentic rather than artificial spoken discourse. It enables them to identify language features, which can enhance their pragmatic and discourse competence as well as their fluency. This is consistent with the results of other studies such as Guillot, (2002), Hughes (2002).

There is evidence that providing supportive feedback throughout task cycle is highly effective. Through this feedback, students' strengths in speaking can be highlighted and appreciated and possible suggestions for improvement can be offered throughout in a way that helps students develop their speaking and gain clearer insights of others' expectations. This is supported by Skehan (2002), and Furuta (2002).

Public oral performance after performing task proved effective in helping students realize both accuracy and complexity in terms of all speaking skills without interfering with their fluency during the task. This is consistent with the study of Glover, (2011).

\subsection{Pedagogical Implications}

The following pedagogical implications can be drawn on the basis of the results of the present study: The present program can be adopted for teaching speaking to students at the university level and other stages taking into consideration students' age, needs, interests and linguistic proficiency levels. Speaking instruction should be given more attention in our ESL classes. More time and effort should be exerted to develop this skill and its subskills. Students should be offered enough opportunities to practice speaking on a daily basis for authentic purposes (i.e., to describe, narrate, apologize, invite, congratulate and so on.) in ESL classes. Student- teachers and teachers should be aware of the speaking skills necessary for students at each stage so that they can develop and evaluate these skills properly. In addition, students should be aware of the criteria according to which their speaking is evaluated in order to work hard to meet these criteria.

ESL teachers should focus equally on the different speaking sub- skills, thus paying more attention to the discourse competence including conversation management and discourse organization as well as to pragmatic competence and fluency beside their usual focus on grammar and vocabulary. Teaching speaking should be grounded in an adequate theory- "the cognitive approach"- to develop its skills adequately.

Teachers are recommended to adopt task-based instruction in teaching speaking to their students. Thus, speaking subskills can be taught in the context of the speaking tasks taking into consideration that students should focus on the accuracy in the initial stage of the task (pre-task stage) and then focus on fluency and spontaneous speaking during performing the task, then reflect and acquire more skills at the post-task stage.

Students should be able to plan for their spoken performance in advance to lower the burden on their cognitive ability during speaking. Moreover, they should be offered enough comprehensible input through pre-task activities and especially through listening to authentic texts, thus raise their consciousness of the relevant skills as well as the rules and features of the spoken language discourse.

Enough post- task activities aiming at helping students acquire new skills and test hypotheses about spoken language should be presented to intermediate ESL students so that they can restructure their underlying language system in a way that helps them integrate spoken discourse rules and skills later on in their real time performance.

Students should become the center of the learning process and should share more responsibilities in their learning of speaking skills. Hence, they should be offered opportunities to self evaluate their oral performance. In this way, they can become more independent and more involved in learning speaking. This entails a necessary change in the teacher's role from an authority figure to a facilitator, discussion organizer, helper and language adviser.

Students' speaking performance should be encouraged and appreciated through public performance. This can be done in different ways to increase students' motivation and awareness of the sense of audience and purpose. Among these ways are (a) allowing some students to repeat the task in front of the rest of the class, (b) requiring students to report the task output and results and (c) comparing students' performance to native language speakers' performance and discussing points of strength and weakness.

Supportive feedback should be offered throughout the task cycle, not only to help students identify their weaknesses in speaking and ways of overcoming them but also to encourage their strengths and consequently increase their motivation and involvement in speaking.

\subsection{Suggestions for further studies:}

In the light of the present study results, the following studies can be suggested: further research is needed to explore the effectiveness of the proposed task-based instruction program in developing Malaysian ESL students' speaking skills (grammatical, pragmatic and discourse competencies) as well as their fluency. 
While the present study provided support to the effectiveness of the proposed-task-based instruction program in developing freshmen university students' overall speaking proficiency, further research is needed to investigate the effectiveness of similar programs in developing students' listening, writing and reading skills.

Further research is needed to explore the effectiveness of other task-based instruction programs at university levels. Other studies are needed to investigate the effectiveness of applying a similar program over a longer period of time on students' skills especially on pronunciation and fluency. Other studies are needed to investigate deeply the effectiveness of applying a similar program on different speaking genres (descriptive, narrative, expository and so on). And further research is needed to compare different cognitive approach strategies in terms of their effectives in developing ESL students' speaking skills.

\section{References}

Aliakbari, M., \& Jamalvandi, B. (2010). The impact of role play on fostering EFL learners' speaking ability: A taskbased approach. Journal of Pan-Pacific Association of Applied Linguistics, 14(1), 15-29.

Badr, S. (2008). The effect of blended learning communicative output activities supported with utilizing anxiety management techniques on EFL learners' language apprehension and oral communication skills. Journal of Psychological and Educational Research, issued by Faculty of Education, Minufiyah University, 23(1), 3-53.

Bahrani, T. (2011). Speaking fluency: Technology in EFL context or social interaction in ESL context. Studies in Literature and Language, 2(2), 162-168.

Brophy, J. (2008). Using video in teacher education. Bingley: Emerald Group Publishing Limited.

Derwing, T., Muray, J., \& Thomson, R. I. (2008). A longitudinal study on ESL learners' fluency and comprehensibility development. Applied Linguistics, 29(3), 359-380.

Dincer, A., Yesliyurt, S., \& Takkac, M. (2012). The effects of autonomy-supportive climates on EFL learners' engagement, achievement and competence in English speaking classrooms. Social and Behavioural Sciences, 46(2), 3890-3894.

Ellis, R. (2003). Task-Based Language Learning and Teaching. Oxford: Oxford University Press

Furuta, J. (2002). Task Based Language Instruction: An Effective Means of Achieving Integration of Skills and Meaningful Language Use. Eric Document. (ERIC Document Reproduction Service No. ED: 475 019)

Glover, P. (2011). Using CEFR level descriptors to raise university students' awarness of speaking skills. Language Awareness, 2(1), 33-52.

Gorsuch, G. J. (2011). Improving speaking fluency for international teaching assistants by increasing input. The Electronic Journal for English as a Second Language, 14(4), 1-16.

Graves, K. (2008). The language curriculum: A social contextual perspective. Language Teaching, 41(2), 147-181.

Guillot, M. (2002). "Corpus-Based Work and Discourse Analysis in FL Pedagogy: A Reassessment". System, V. 30, n.1, Pp: $15-32$

Hartsell, T., \& Yuen, S. (2006). Video streaming in online learning. AACE Journal, 14(1), 31-43.

Hughes, R. (2002). Teaching and Researching Speaking. Warlow: Longman.

Kasper, G. (2001). "Four Perspectives on L2 Pragmatic Development". Applied Linguistics. V.22, n.4, Pp: 502-530.

Kessler, G. (2010). Fluency and anxiety in self-access speaking tasks: The influence on environment. ComputerAssisted Language Learning, 23(4), 361-375.

Kirkgoz, Y. (2011). A blended learning study on implementing video recorded speaking tasks in task-based classroom instruction. Turkish Online Journal of Educational Technology TOJET. 10(4), 1-13.

Koester, A. (2000) "The Performance of Speech Acts in Workplace Conversation and the Teaching of Communicative Functions". System., V.30, n. 2, Pp: 167-184.

Kumaravadivelu, B. (1993). "The Name of the Task and the Task of Naming: methodological Aspects of Task Based Pedagogy". In G. Crookes and S. Gass (Eds.). Task and Language Learning: Integrating Theory and Practice, (Pp: 6996). Clevedon, Avon: Multilingual Matters.

McCarthy, M. \& Carter, R. (Summer 2001a) "Size Isn't Everything: Spoken English, Corpus, and the Classroom". TESOL Quarterly, V. 35, n.2, Pp: 337-40

Murat, H. (2012). Teaching word stress to Turkish EFL English as foreign language learners through internet-based video lessons. Retrieved from ERIC database. (ED 530678).

Nazara, T. (2011). Students' perception on EFL speaking skill development. Journal of English Teaching, 1(1), 28-42.

Romero, B. N. (2006). Improving speaking skills. Encuentro, 18, 86-90.

Shephard, K. (2003). Questioning, promoting and evaluating the use of streaming video to support student learning. British Journal of Educational Technology, 34(3), 295-308.

Skehan, P. (2002). “A Non-marginal Role for Tasks”. ELT Journal, V.56, n.3, Pp: 289-295. 
Willis, J. (1996 a). A Framework for Task-Based Learning. Addison Wesley: Longman.

Willis, J. (1998). "Task-Based Learning: What Kind of Adventure?" The Language Teacher. http://www.jaltpublications.org/tlt/files/98/jul/willis.html, accessed on 11th. September, 2005.

Yuan, F. \& Ellis, R. (2003). "The Effects of Pre-Task Planning and On-Line Planning on Fluency, Complexity and Accuracy in L2 Monologic Oral Production”. Applied Linguistics. V.24. n. 1, Pp: 1-27.

Zhang, Y. (2009). Reading to speak: Integrating oral communication skills. English Teaching Forum, 1(1), 31-34.

\section{Appendices \\ Speaking test}

\section{Part 1 (2-3 minutes)}

[to both students] Good morning/afternoon/evening.

Can I have your mark sheets, please? [examiner takes the mark sheets, which will have been given to students before they enter the room]

I'm ................... [name] and this [second examiner] is [name]. He/She is just going to listen

to us.

[to student A] Now, what is your name?

[to student B] And what is your name?

Thank you.

[to student A and again to student B]

What is your surname?

How do you spell it? / How do you write your family/second name?

Thank you.

[to student A and then again to student B]

Where do you live? [or where do you come from?/Do you live in place name?]

Do you work or are you a student in place name? What do you do/study?

or

Do you study English at school? [or Do you have English lessons?] Do you like it?

Thank you.

[to student A and then again to student B, one or more of these questions]

Do you think English will be useful for you in the future?

Tell us about your school.

What do you enjoy doing at the weekends?

What did you do yesterday?

Thank you.

[to both students]

In the next part you are going to talk to each other.

\section{Part 2 (2-3 minutes)}

[to both students] I'm going to describe a situation to you.

At the end of term, your class is going to spend a day at the seaside. Talk together about the things you will do there.

[give students picture 1A]

Here is a picture with some ideas to help you. [give students a few moments to look at the picture]

I'll say that again.

At the end of term, your class is going to spend a day at the seaside. Talk together about the things you will do there.

All right? Talk together.

[give students about two minutes to talk together. Do not join in unless they have problems, for example to make a suggestion, e.g. some people might like to go for a walk.]

Thank you. [take back picture]

\section{Part 3 (3 minutes)}

[to both students]

Now I'd like each of you to talk on your own about something. I'm going to give each of you a photograph of one way of travelling. 


\section{[to student A]}

Here is you photograph. [give student A photo 1B]. Please show it to student B but I would like you to talk about it. Student B, you just listen. I'll give you your photograph in a moment.

Students A, please tell us what you can see in your photograph.

Thank you. [take back photo]

[to student B]

Now, student B, here is your photograph. [give student B Photo 1C]. It also shows a way of travelling.

Please show it to student A and tell us what you can see in the photograph.

Thank you. [take back photo]

\section{Part 4 (3 minutes)}

[to both students]

Your photographs showed different ways of traveling. Now, I'd like you to talk together about how you would choose to travel.

[give students about two minutes to talk together. Do not join unless they have problems, for example to offer a comment, e.g. I prefer to fly but I know it's not good for the environment.]

Thank you. That's the end of the test.

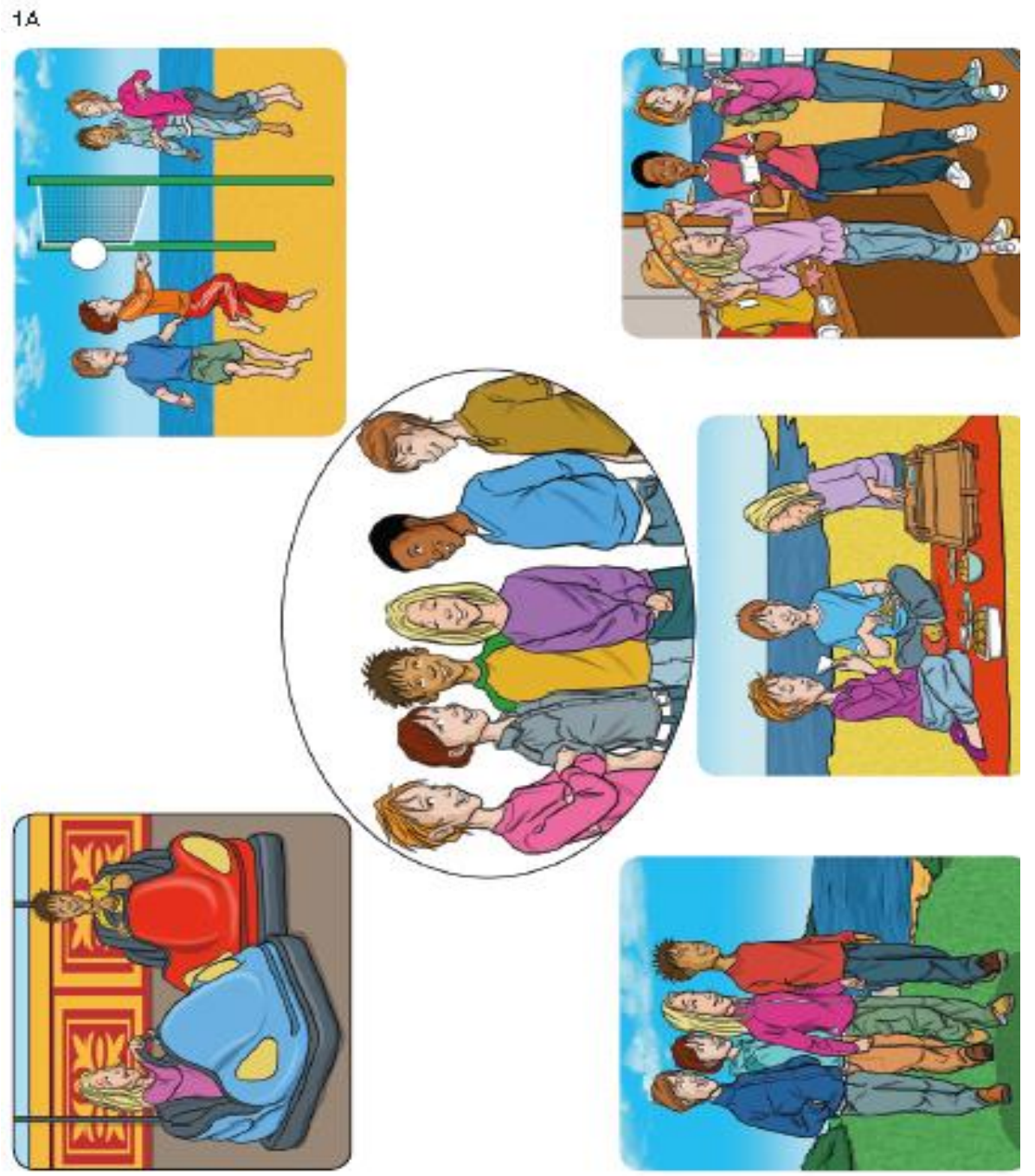


18

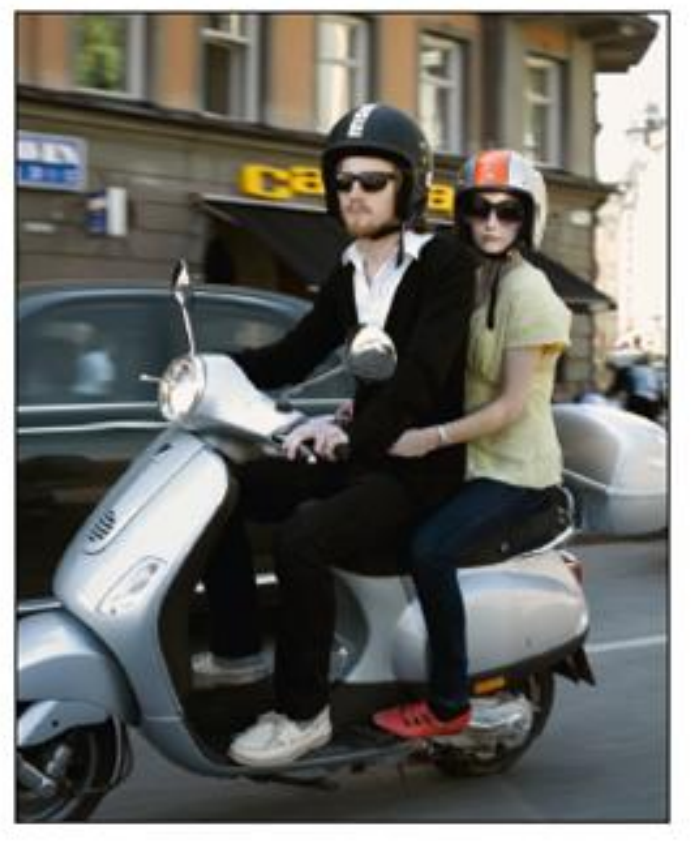

$1 \mathrm{C}$

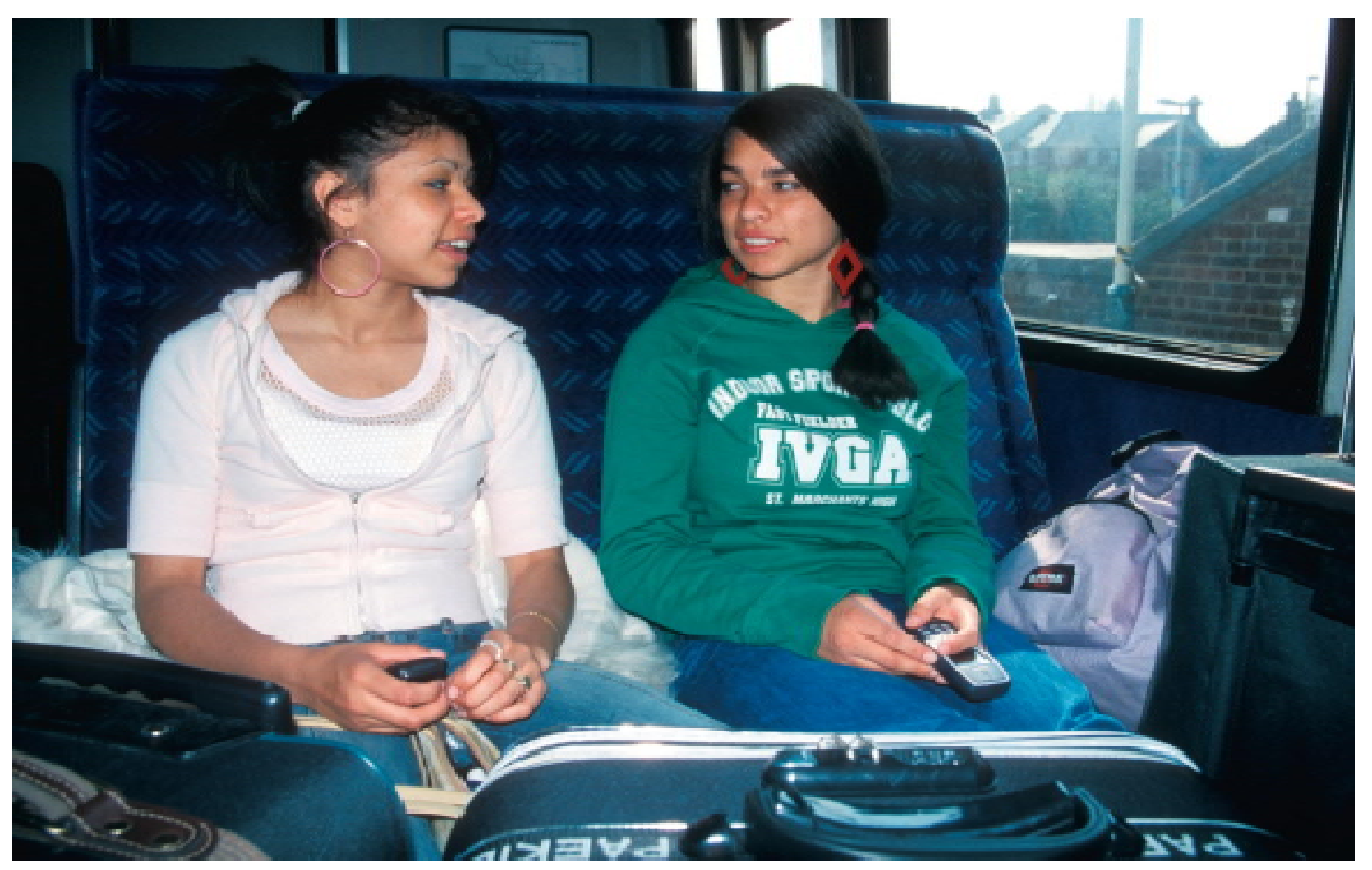

